\title{
Truncating English and Arabic Onset Cluster by a Bilingual Child: An Optimality Theory Perspective
}

\author{
Hana Asaad Daana \\ Princess Alia University College, Al-Balqa Applied University, Amman, Jordan
}

\begin{abstract}
This study investigates the process of truncating English and Arabic onset cluster in the early speech of a bilingual child within the framework of Optimality Theory Model. It specifically proposes the child's hierarchical grammar(s) responsible for the child's process of simplifying English and Arabic consonantal sequences into singletons in onset position. The importance of this research stems from the absence of research on truncating Arabic onset cluster within the Optimality Theory perspective. Therefore, it is the first to put this theory into practice as far as reducing Arabic clusters is concerned. The data for this research were collected through parental diaries. Only data collected between the ages of 1;9 and 2;5 were analysed. The results reveal two different hierarchies of the grammar each of which is responsible for truncating the clusters into singletons in one particular language. The results also reveal a conformity with the universally fixed onset constraint hierarchy in the child's English production. However, a deviation from this universally fixed onset constraint hierarchy is detected in the production of the sequence formed by fricative followed by stop or vice versa in Arabic.
\end{abstract}

Index Terms - onset cluster, fixed hierarchy, optimality theory, truncation, sonority

\section{INTRODUCTION}

Over the years, a great deal of studies on language acquisition has been accumulated investigating the development of consonant cluster in onset position in different languages. However, very few studies, if any, have attempted to tackle the way bilingual children whose two first languages are Arabic and English simplify consonantal sequences in onset position in two typologically different languages from an Optimality Theory perspective. Consequently, the main goal of this study is to account for the grammar responsible for the cluster reduction strategy resorted to by the child to get rid of the cluster in onset position in English and Arabic.

At the time that the Optimality Theory Model (henceforth OT) has been used as a tool to trace the way onset cluster is truncated into singleton by monolingual and/or bilingual children acquiring several European languages, very few studies have been conducted to investigate this strategy of simplifying Arabic onset cluster within the framework of OT. Therefore, it is, with no doubt, of equal importance to put this theory into practice regarding the simplification of Arabic and English consonant clusters by a bilingual Jordanian child in his early stages of production. Hence, the main aim of the study is to compare and contrast the way the child handles consonantal sequences in onset position in two different languages descending from two different families. The study focuses on the early stages of the child's acquisition process; that is to say, it analyses the data that were collected during the ages $1 ; 9$ and $2 ; 5$.

It is worth mentioning here that the researcher of this paper has recently published a study in which she traced the developmental path of English and Arabic onset clusters in the speech of her bilingual child. Daana and Khrais analysed the data collected from the first researcher's child and investigated target elements between the ages of 1;9 and 3;6 (Daana and Khrais 2018). This study however differs in that it utilizes OT modal to compare and contrast the way the same child truncated the clusters in both languages only throughout the early stage of acquisition. That is through the stage at which the child's clusters are truncated into singletons.

\section{TYPES OF ONSET CLUSTER IN ARABIC COMPARED TO ONSET CLUSTER IN ENGLISH}

To start with, onsetless syllables are not allowed in Arabic. Consonant clusters in onset position are allowed in the form of Arabic under investigation -Ammani Arabic-. Ammani Arabic allows clustering consonants in onset position with no restriction on consonantal sequences. This leads to the existence of the three types of onset clusters suggested by Watson (2002): core in which the consonantal sequence between the elements of the cluster complies with the Sonority Scale Principle (SSP) suggested by Clements (1990) as in /kla:b/ dogs. The second type of clusters found in Ammani Arabic is plateau which is formed by two elements of equal sonority as in /kbi:r/ big. The third type is reversal in which the sonority distance between the elements of the cluster violates the SSP as in /rma: $\mathrm{h} /$ spears. On the other hand, English allows onsetless syllables. It also allows consonant clusters in onset position respecting the Sonority Scale Principle except for sequences starting with /s/ (Carr 1999). 


\section{RELATED STUDIES}

The acquisition of consonant clusters has recently been the target of a large number of research (Pater and Barlow 2003; Kirk and Demuth 2005; Levelt, Schiller and Levelt, 2000; Gnanadesikan 2003; Barlow 1997; Lleo and Prinz 1996; Ohala 1996; Daana 2009; Daana and Khrais 2018). In their study, Pater and Barlow (2003) detected a pattern in the production of one of their subjects in which the child selected the fricative over the liquid in clusters formed of fricative followed by liquid. Their child's production satisfied the SSP or the universally fixed onset constraint hierarchy suggested by Pater 1997:

\section{*G-ONS $>>$ *L-ONS $>>* \mathbf{N}-\mathbf{O N S}>>* \mathbf{F}-\mathbf{O N S}>>* \mathbf{S}-\mathbf{O N S}$}

In these constraints, $\mathrm{G}$ stands for glide, $\mathrm{L}$ stands for liquid, $\mathrm{N}$ is nasal, $\mathrm{F}$ is fricative and $\mathrm{S}$ is stop. This hierarchy is subverted by three conflicting constraints:

\section{*FRICATIVES *DORSAL MAX-LABIAL}

On the other hand, their child selected the nasal and deleted the fricative in sequences formed by fricative followed by nasal by virtue of the higher ranking of *FRICATIVE relative to *N-ONS

Unlike the method used in this study, Daana and Khrais (2018) used the descriptive method tracing the developmental path of onset clusters in the production of the first author's bilingual child acquiring English and Ammani Arabic (a form of Jordanian Arabic). Their results reveal a conformity to the universally fixed onset constraint hierarchy stated above together with few cases in which his production deviated from this hierarchy of onset constraint.

In her study, Daana (2009) investigated the acquisition of consonant cluster in onset position in Ammani Arabic. Her informants' ages ranged between 2 and 7 years. Her findings show that several factors determine the earlier acquisition of some particular sequences than the others. Sonority distance, ease of articulation, frequency in the input and salient perception of the sequences are the factors that determine which sequence is to be acquired before other sequences.

\section{THIS STUDY}

\section{A. Study Objective}

The aim of this study is to find out the child's grammar(s) responsible for the child's handling of onset clusters in two languages during the early stage of acquisition.

\section{B. Data Collection}

The source of data tackled in this study is traditional parental diary of the spontaneous production of the researcher's child. The child was the researcher's only son. The child was learning English and Arabic and he had no perceptual or articulatory impairment. He was exposed to Ammani Arabic by his parents and the very few Jordanian friends who used to visit the family on social occasions as the family used to live in the UK at that time. Ammani Arabic, the child's parents' native language, was mainly used by the child's father and sometimes by the child's mother who used to speak to her child using English and Arabic. The child's mother was a PhD student majoring in Language Acquisition at that time. The researcher spent hours with her child talking, playing, arguing, describing pictures, telling stories and reading stories in both languages. Each session lasted for about 45 minutes and was audio recorded. Sessions took place on daily basis in the child's room. Nobody was present at the time of the sessions. All recordings were narrowly transcribed by the researcher and were checked by another potential PhD Jordanian student majoring in Phonology. Data was chronologically classified and saved in computer files. These files included the child's production, the adults' equivalent, the glossary of the Arabic production and some details about the context if necessary.

\section{ANALYSIS AND DISCUSSION}

For the purpose of this study only the child's Arabic and English production of repaired target words were analysed. As far as the Arabic language is concerned, the child started repairing target words- with initial onset cluster- at the age of $2 ; 3$. The child produced all such target words deleting one element of the cluster and preserving the other. At the age of $2 ; 6$, the child started using other different strategies to simplify the clusters in addition to the occasional use of truncation in both languages. However, the child started repairing target-words with initial onset clusters in English at the age of 1;9. At the age of 2;6 the child's strategy simplifying the English clusters varied. The main aim of this research is limited to investigating and describing the child's simplification of the English and Arabic clusters in onset position between the age of 1;9 and 2;5. The child's data were analysed in parts. Each part explains a particular consonantal sequence in both languages. A trace of the grammatical hierarchy responsible for such production is suggested along the parts.

The child's first production of Arabic words was noticed at the age of $2 ; 3$. Target words with clusters in onset position were reduced to singletons between the ages of $2 ; 3$ and $2 ; 5$ by virtue of the fact that *COMPLEXonset was ranked at the top of the hierarchy in the child's grammar at this age- stage.

\section{*COMPLEXonsets}

Complex onsets are not allowed.

\section{A. Fricative/Stop - Approximant Cluster}


The first consonantal sequence to be tackled is the one formed by fricative/stop followed by approximant. Between the ages of $2 ; 3$ and $2 ; 5$, target words with fricative/stop followed by approximant as elements of the cluster in onset position emerged in the child's production all of which underwent a deletion of the approximant. This act reflects conformity with the universally fixed onset constraint hierarchy. Representative production of the child's words are exemplified in Table 1.

TABLE (1)

ARABIC (FRICATIVE/STOP - APPROXIMANT CLUSTER)

\begin{tabular}{|l|l|l|l|}
\hline Age & $\begin{array}{l}\text { Target } \\
\text { words }\end{array}$ & $\begin{array}{l}\text { Child's } \\
\text { production }\end{array}$ & Glossary \\
\hline $2 ; 3$ & $/$ ri:t/ & {$\left[\int \mathrm{i}: \mathrm{t}\right]$} & cassette \\
\hline $2 ; 4$ & $/ \mathrm{hra}: \mathrm{m} /$ & {$[\mathrm{ha}: \mathrm{m}]$} & blanket \\
\hline $2 ; 4$ & $/ \mathrm{kla}: \mathrm{b} /$ & {$[\mathrm{ba}: \mathrm{b}]$} & dogs \\
\hline & $/$ tra:b/ & {$[\mathrm{ta}: \mathrm{b}]$} & soil \\
\hline & $/$ bwa:b/ & {$[\mathrm{ba}: \mathrm{b}]$} & doors \\
\hline & $/$ bwa:t/ & {$[\mathrm{ba}: \mathrm{t}]$} & boots \\
\hline
\end{tabular}

The fact that the child consistently truncated the Arabic clusters into singletons confirms findings of other research (pater and Barlow 2003; Gnanadesikan 2003; Barlow 1997; Daana 2009; Daana and Khrais 2018; Ohala 1996) most of which attributed the deletion of the sonorant segment to the domination of Markedness constraints over Faithfulness constraints. Table 1 above shows that at this stage, the child's grammar is dominated by *COMPLEXonset. The fact that the child selected the fricative/stop over the approximant indicates the dominancy of *G-ONS and *L-ONS in the child's grammar. These three structural constraints, however, dominate Faith.

FAITH

The output must be faithful to the input

This can be illustrated in Tableau 1 below.

TABLEAU (1)

*COMPLEXONSET $>>*$ G-ONS $>>*$ L-ONS $>>*$ F-ONS $>>*$ S-ONS $>>$ FAITH

\begin{tabular}{|c|c|c|c|c|c|c|}
\hline /bwa:b/ & *COMPLEXonset & *G-ONS & *L-ONS & *F-ONS & ${ }^{*} \mathrm{~S}-\mathrm{ONS}$ & FAITH \\
\hline$\rightarrow / \mathrm{ba}: \mathrm{b} /$ & & & & & $*$ & $*$ \\
\hline /wa:b/ & & $*$ & & & & $*$ \\
\hline /bwa:b/ & $* !$ & $*$ & & & $*$ & \\
\hline \multicolumn{7}{|l|}{ /hra:m/ } \\
\hline$\rightarrow /$ ha:m/ & & & & $*$ & & $*$ \\
\hline /ra:m/ & & & $*$ & & & $*$ \\
\hline /hra:m/ & $* !$ & & $*$ & $*$ & & \\
\hline \multicolumn{7}{|l|}{ /kla:b/ } \\
\hline$\rightarrow / \mathrm{ka}: \mathrm{b} /$ & & & & & $*$ & $*$ \\
\hline /la:b/ & & & $*$ & & & $*$ \\
\hline /kla:b/ & $* !$ & & $*$ & & $*$ & \\
\hline
\end{tabular}

As Tableau 1 above shows, the child's production of this particular Arabic consonantal sequence results from the child's grammar:

*COMPLEXonset $>>*$ G-ONS $>>*$ L-ONS $>>*$ F-ONS $>>*$ S-ONS $>>$ FAITH

English onset clusters formed by stop or fricative followed by approximant were also reduced to singletons deleting the approximant. Representative data is shown in Table 2 below.

TABLE (2)

ENGLISH (FRICATIVE OR STOP - APPROXIMANT CLUSTER)

\begin{tabular}{|c|c|c|}
\hline Age & Target words & Child's production \\
\hline $1 ; 9$ & flower & [favə] \\
\hline $1 ; 10$ & floor & [fo:] \\
\hline 2 & tree & [ti:] \\
\hline 2 & green & [gi:n] \\
\hline $2 ; 1$ & please & [pi:s] \\
\hline $2 ; 3$ & front & [font] \\
\hline $2 ; 3$ & twinkle & [tıjku] \\
\hline $2 ; 4$ & fruit & [fu:t] \\
\hline $2 ; 4$ & slow & [səu] \\
\hline $2 ; 4$ & sleep & [si:p] \\
\hline $2 ; 4$ & clean & [ki:n] \\
\hline $2 ; 4$ & press & [pes] \\
\hline $2 ; 4$ & brown & [baun] \\
\hline
\end{tabular}


This is also attributed to *COMPLEXonset, ${ }^{*}$ G-ONS and *L-ONS constraints which are ranked above FAITH. This is shown in Tableau 2 below.

TABLEAU (2)

*COMPLEXONSET $>$ > G-ONS $>>*$ L-ONS $>>$ F-ONS $>>*$ S-ONS $>>$ FAITH

\begin{tabular}{|c|c|c|c|c|c|c|}
\hline /frog/ & *COMPLEXonset & $* \mathrm{G}-\mathrm{ONS}$ & *L-ONS & *F-ONS & *S-ONS & FAITH \\
\hline$\rightarrow /$ fog $/$ & & & & $*$ & & $*$ \\
\hline /rog/ & & & $*$ & & & $*$ \\
\hline \multicolumn{7}{|l|}{ /sli:p/ } \\
\hline$\rightarrow / \mathrm{si}: \mathrm{p} /$ & & & & $*$ & & $*$ \\
\hline \multicolumn{7}{|l|}{ /pres/ } \\
\hline$\rightarrow / \mathrm{p} \varepsilon \mathrm{s} /$ & & & & & $*$ & $*$ \\
\hline /rعs/ & & & $*$ & & & $*$ \\
\hline /pres/ & $* !$ & & $*$ & & $*$ & \\
\hline \multicolumn{7}{|l|}{ /kli:n/ } \\
\hline \multicolumn{7}{|l|}{ /twinkl/ } \\
\hline$\rightarrow /$ tınkul & & & & & $*$ & $*$ \\
\hline /WInku/ & & $*$ & & & & $*$ \\
\hline /twinkl / & $* !$ & $*$ & & & $*$ & \\
\hline
\end{tabular}

So far, it can be assumed that the production of this type of consonantal cluster is governed by the same hierarchy in both languages.

\section{*COMPLEXonset $>>* \mathbf{G}-\mathrm{ONS}>>* \mathbf{L}-\mathrm{ONS}>>* \mathbf{F}-\mathrm{ONS}>>* \mathbf{S}-\mathrm{ONS}>>\mathbf{F A I T H}$}

\section{B. Fricative - Stop Cluster}

The next consonantal sequence to be investigated is the one formed by fricative followed by stop in English and Arabic. The child dealt with this form of cluster in two different ways. The child chose to retain the stop and delete the fricative in his English production. Representative English data are shown in Table 3.

TABLE (3)

ENGLISH (FRICATIVE - STOP CLUSTER)

\begin{tabular}{|l|l|l|}
\hline Age & Target word & Child's production \\
\hline $1 ; 10$ & spoon & [pu:n] \\
\hline 2 & star & {$[$ ta:] } \\
\hline $2 ; 1$ & school & {$[\mathrm{ku}:]$} \\
\hline $2 ; 2$ & spider & [paidə] \\
\hline $2 ; 3$ & speak & [pi:k] \\
\hline $2 ; 4$ & stop & [top] \\
\hline
\end{tabular}

The production of this English sequence also shows conformity with the universally fixed onset constraint hierarchy in which the higher ranking of *F-ONS makes the child delete the fricative. This is illustrated in Tableau 3 below.

TABLEAU (3)

*COMPLEXONSET $>>$ *G-ONS $>>*$ L-ONS $>>*$ F-ONS $>>*$ S-ONS $>>$ FAITH

\begin{tabular}{|c|c|c|c|c|c|c|}
\hline /sta:/ & *COMPLEXonset & $* \mathrm{G}-\mathrm{ONS}$ & $* \mathrm{~L}-\mathrm{ONS}$ & *F-ONS & $*$ S-ONS & FAITH \\
\hline$\rightarrow /$ ta:/ & & & & & $*$ & $*$ \\
\hline /sa:/ & & & & $*$ & & $*$ \\
\hline \multicolumn{7}{|l|}{ /sku:1/ } \\
\hline$\rightarrow / \mathrm{ku}: 1 /$ & & & & & $*$ & $*$ \\
\hline \multicolumn{7}{|l|}{ /spu:n/ } \\
\hline$\rightarrow /$ pu:n/ & & & & & $*$ & $*$ \\
\hline /su:n/ & & & & $*$ & & * \\
\hline /spu:n/ & $* !$ & & & $*$ & $*$ & \\
\hline
\end{tabular}

Hence, the same hierarchy is responsible for the production of this second English consonantal sequence:

*COMPLEXonset $>>*$ G-ONS $>>*$ L-ONS $>>*$ F-ONS $>>*$ S-ONS $>>$ FAITH 
On the other hand, the universally fixed onset constraint hierarchy was disturbed in the child's production of such a consonantal sequence in Arabic. The child chose to delete the stop and retain the fricative. A sequence formed by stop followed by fricative in Arabic which had no resembling sequence in English was also dealt with by deleting the stop and retaining the fricative (Table 4).

TABLE (4)

ARABIC (STOP- FRICATIVE AND FRICATIVE - STOP CLUSTER)

\begin{tabular}{|l|l|l|l|}
\hline Age & $\begin{array}{l}\text { Target } \\
\text { words }\end{array}$ & $\begin{array}{l}\text { Child's } \\
\text { production }\end{array}$ & Glossary \\
\hline $2 ; 3$ & $/$ tfaddal/ & [faddaj] & come in \\
\hline & $/$ kfu:f/ & {$[$ fu:f] } & gloves \\
\hline $2 ; 4$ & /stanna/ & {$[$ sanna] } & wait (M) \\
\hline & $/$ tare:tha/ & {$[$ [aje:ta] } & I bought it (F) \\
\hline
\end{tabular}

The child treated these two Arabic sequences in the same way. He selected the fricative and deleted the stop. This behaviour however contradicts other children's behaviour acquiring these sequences in other languages as found in previous research (Pater and Barlow 2003; Gnanadesikan 2013; Ohala 1996). It also contradicts the child's own production of such sequences in English as we could see. Other children in the literature had the tendency of deleting the fricative and retaining the stop by virtue of the universally fixed onset constraint hierarchy. *F-ONSET is ranked above *S-ONSET. The child's English production manifested a deletion of the fricative and retaining the stop. However, the child in his Arabic production tended to delete the stop and retain the fricative. This can be attributed to the fact that IDENT-strid is ranked above*F-ONSET in the child's Arabic grammar.

IDENT-strid:

The feature strident in the input must have a correspondence in the output

TABLEAU (4)

*COMPLEXONSET $>$ > G-ONS $>>$ *L-ONS $>>$ IDENT-STRID $>>*$ F-ONS $>>$ *S-ONS $>>$ FAITH

\begin{tabular}{|c|c|c|c|c|c|c|c|}
\hline /stanna/ & *COMPLEXonset & $* \mathrm{G}-\mathrm{ONS}$ & *L-ONS & IDENT-strid & $* \mathrm{~F}-\mathrm{ONS}$ & $* \mathrm{~S}-\mathrm{ONS}$ & FAITH \\
\hline /stanna/ & $* !$ & & & & $*$ & $*$ & \\
\hline$\rightarrow /$ sanna/ & & & & & $*$ & & $*$ \\
\hline /tanna/ & & & & $*$ & & $*$ & $*$ \\
\hline \multicolumn{8}{|l|}{ / tare:t/ } \\
\hline /staje:t/ & $* !$ & & & & $*$ & $*$ & \\
\hline$\rightarrow /$ aje:t/ & & & & & $*$ & & $*$ \\
\hline \multicolumn{8}{|l|}{ /kfu:f/ } \\
\hline /kfu:f/ & $* !$ & & & & $*$ & $*$ & \\
\hline$\rightarrow /$ fu:f/ & & & & & $*$ & & $*$ \\
\hline /ku:f/ & & & & $*$ & & $*$ & $*$ \\
\hline
\end{tabular}

Therefore the child's grammar responsible for the production of the Arabic sequences represented in Table 4 is:

\section{*COMPLEXonset $>>$ *G-ONS $>>*$ L-ONS $>>$ IDENT-strid $>>*$ F-ONS $>>*$ S-ONS $>>$ FAITH}

\section{Fricative - Nasal Cluster}

Clusters formed by fricative followed by nasal in English and in Arabic were also dealt differently. The child chose to truncate this English sequence into a singleton in favour of the nasals (Table 5).

TABLE (5)

ENGLISH (FRICATIVE - NASAL CLUSTER)

\begin{tabular}{|l|l|l|}
\hline Age & Target word & Child's Production \\
\hline 2 & snow & {$[$ nəu $]$} \\
\hline $2 ; 3$ & small & {$[\mathrm{m}: \mathrm{j}]$} \\
\hline
\end{tabular}

The fact that the child chose to delete the fricative and retain the nasal was counter to the sonority pattern. This indicates that *FRICATIVE is ranked above *N-ONS in the child's English grammar. We could see in Tableau 2 that the child preserved the fricative when followed by a liquid. This requires ranking *FRICATIVE between *L-ONS and *N-ONS. This pattern was also found in Pater and Barlow's findings (2003). Tableau 5 below shows the hierarchy responsible for the production of this type of sequence. 
TABLEAU (5)

*COMPLEXONSET $>>*$ G-ONS $>>*$ L-ONS $>>*$ FRICATIVE $>>* N-O N S>>*$ F-ONS $>>$ S-ONS $>>$ FAITH

\begin{tabular}{|c|c|c|c|c|c|c|c|c|}
\hline /snou/ & *COMPLEX onset & $* \mathrm{G}-\mathrm{ONS}$ & *L-ONS & *FRICATIVE & $* \mathrm{~N}-\mathrm{ONS}$ & *F-ONS & *S-ONS & FAITH \\
\hline /səu/ & & & & $*$ & & $*$ & & $*$ \\
\hline$\rightarrow /$ nəu/ & & & & & $*$ & & & $*$ \\
\hline /snov/ & $* !$ & & & $*$ & $*$ & $*$ & & \\
\hline \multicolumn{9}{|l|}{ /smo:I/ } \\
\hline /so:j/ & & & & $*$ & & $*$ & & $*$ \\
\hline$\rightarrow / \mathrm{mo:j/}$ & & & & & $*$ & & & $*$ \\
\hline /smo:j/ & $* !$ & & & $*$ & $*$ & $*$ & & \\
\hline
\end{tabular}

Hence so far, the child's grammar responsible for the production of the three types of English cluster discussed so far can be suggested as:

*COMPLEXonst $\gg>$ *G-ONS $>>*$ L-ONS $>>*$ RICATIVE $>>* \mathbf{N}-\mathbf{O N S}>>* \mathbf{F}-\mathbf{O N S}>>* \mathbf{S}-\mathbf{O N S}$

On the other hand, the same type of consonantal sequence in Arabic was repaired by epenthesizing a vowel (Table 6).

TABLE (6)

ARABIC (FRICATIVE - NASAL CLUSTER)

\begin{tabular}{|l|l|l|l|}
\hline Age & Target word & Child's Production & Glossary \\
\hline $2 ; 3$ & /Imalha/ & [Yamaja] & you do it \\
\hline $2 ; 4$ & /3ma:1/ & [zama:j] & camels \\
\hline
\end{tabular}

Choosing not to delete the bilabial nasal but rather to insert an epenthetic vowel shows the importance of MAXlabial which is ranked above*N-ONS in the child's Arabic grammar.

MAX-labial

The feature labial in the input must have a correspondence in the output

Choosing to retain the fricative shows that *FRICATIVE has no effect in the child's Arabic grammar. However, it makes it possible to assume that the ranking between MAX-labial and IDENT-strid is not vital. That is, they may be equally ranked. At this stage of production all the child's production of clusters witnessed a truncation except for this Arabic sequence. This particular production contradicts the results of other studies in which children resorted to deleting either the nasal or the fricative. As well as it contradicts the same child's production of the same sequence in English as is illustrated in Table 5 above. Therefore, the child's Arabic grammar responsible for the production of fricative followed by nasal in this manner is illustrated in Tableau 6.

TABLEAU (6)

*COMPLEXONSET $>>*$ G-ONS $>>*$ L-ONS $>>$ MAX-LABIAL,IDENT-STRID $>>* N-O N S>>*$ F-ONS $>>* S-O N S>>$ FAITH

\begin{tabular}{|c|c|c|c|c|c|c|c|c|c|}
\hline /Imalha/ & *COMPLEXonset & $\begin{array}{l}* \mathrm{G}- \\
\text { ONS }\end{array}$ & $\begin{array}{l}* \mathrm{~L}- \\
\text { ONS }\end{array}$ & $\begin{array}{l}\text { MAX- } \\
\text { labial }\end{array}$ & $\begin{array}{l}\text { IDENT- } \\
\text { strid }\end{array}$ & $\begin{array}{l}* \mathrm{~N}- \\
\text { ONS }\end{array}$ & $\begin{array}{l}* \mathrm{~F}- \\
\text { ONS }\end{array}$ & $\begin{array}{l}* \mathrm{~S}- \\
\text { ONS }\end{array}$ & Faith \\
\hline$\rightarrow /$ Samaja/ & & & & & & & $*$ & & $*$ \\
\hline /Smaja/ & $* !$ & & & & & $*$ & $*$ & & \\
\hline /maja/ & & & & & $*$ & $*$ & & & $*$ \\
\hline /Saja/ & & & & $*$ & & & $*$ & & $*$ \\
\hline \multicolumn{10}{|l|}{ /3ma:I/ } \\
\hline$\rightarrow /$ Zama:j/ & & & & & & & $*$ & & $*$ \\
\hline /3ma:j/ & $* !$ & & & & & $*$ & $*$ & & \\
\hline /3a:j/ & & & & $*$ & & & $*$ & & $*$ \\
\hline /ma:j/ & & & & & $*$ & $*$ & & & $*$ \\
\hline
\end{tabular}

This equal ranking of MAX-labial and IDENT-strid makes the child preserve both the fricative and the labial. The tableau above indicates that the child's grammar which accounts for the repairing of the three Arabic sequences discussed so far is:

\section{FAITH}

\section{Nasal-Glide Cluster}

The last English sequence to be investigated is the one formed by nasal followed by glide. This sequence has no resembling sequence in Arabic. The child chose to delete the glide and retain the nasal conforming to the universally fixed onset constraint hierarchy. Illustrative data is introduced in Table 7. 
TABLE (7)

ENGLISH (NASAL - GLIDE CLUSTER)

\begin{tabular}{|c|c|c|}
\hline Age & Target word & Child's Production \\
\hline $2 ; 4$ & news & {$[$ nu:z] } \\
\hline $2 ; 4$ & music & [nu:zık] [mu:zik] \\
\hline
\end{tabular}

The grammar responsible for the deletion of the glide and preserving the nasal is shown in Tableau 7 below.

TABLEAU (7)

*COMPLEXONSET $>>*$ G-ONS $>>*$ L-ONS $>>$ FRICATIVE $>>* N-O N S>>*$ F-ONS $>>$ FAITH

\begin{tabular}{|c|c|c|c|c|c|c|c|c|}
\hline /nju:z/ & *COMPLEX onset & ${ }^{*} \mathrm{G}-\mathrm{ONS}$ & $* \mathrm{~L}-\mathrm{ONS}$ & *FRICATIVE & $* \mathrm{~N}-\mathrm{ONS}$ & $* \mathrm{~F}-\mathrm{ONS}$ & $*$ S-ONS & FAITH \\
\hline$\rightarrow /$ nu:z/ & & & & & $*$ & & & $*$ \\
\hline /ju:z/ & & $*$ & & & & & & $*$ \\
\hline /nju:z/ & $* !$ & $*$ & & & $*$ & & & \\
\hline \multicolumn{9}{|l|}{ /mju:zık/ } \\
\hline$\rightarrow / \mathrm{mu}: \mathrm{zIk} /$ & & & & & $*$ & & & $*$ \\
\hline /mju:zık/ & $* !$ & $*$ & & & $*$ & & & \\
\hline$\rightarrow /$ nu:zık/ & & & & & $*$ & & & $*$ \\
\hline /ju:zık/ & & $* !$ & & & & & & $*$ \\
\hline
\end{tabular}

Hence, the child's grammar responsible for the overall English production of the different English consonantal sequences in onset position at this stage is:

*COMPLEXonst $>>*$ G-ONS $>>$ L-ONS $>>$ FRICATIVE $>>* N-O N S>>$ F-ONS $>>$ *S-ONS $>>$ FAITH

\section{E. Nasal-Stop Cluster}

The last two Arabic sequences have no resembling sequences in English. They are the ones formed by (i) nasal followed by stop and (ii) liquid followed by fricative. These two sequences are of the reversal type. The child chose to conform to the universally fixed onset constraint hierarchy deleting the nasal and the liquid preserving the sounds with decreased sonority. This is shown in Table 8 below.

TABLE 8

ARABIC (NASAL - STOP AND LIQUID - FRICATIVE CLUSTER)

\begin{tabular}{|c|l|l|l|}
\hline Age & Target word & Child's Production & Glossary \\
\hline $2 ; 03$ & /nkasrat/ & [kassat] & it broke (F) \\
\hline $2 ; 04$ & /m?asss/ & [?asss ] & a pair of scissors \\
\hline $2 ; 04$ & /rfu:f/ & [fu:f] & come in \\
\hline & /litrit/ & [Grbit] & I played \\
\hline
\end{tabular}

Therefore, no further constraint is required to account for such a production as long as the Arabic hierarchy which has been produced so far explains the child's selection to delete the segment with the higher sonority. Tableau 8 bellow illustrates the production of these sequences.

TABLEAU (8)

*COMPLEXONSET $>>$ G-ONS $>>$ *L-ONS $>>$ MAX-LABIAL,IDENT-STRID $>>* N-O N S>>*$ F-ONS $>>$ P-ONS $>>$ FAITH

\begin{tabular}{|c|c|c|c|c|c|c|c|c|c|}
\hline /nkasrat/ & $\begin{array}{l}\text { *COMPLEX- } \\
\text { onset }\end{array}$ & $\begin{array}{l}* \mathrm{G}- \\
\text { ONS }\end{array}$ & $\begin{array}{l}* \mathrm{~L}- \\
\mathrm{ONS}\end{array}$ & $\begin{array}{l}\text { MAX- } \\
\text { labial }\end{array}$ & $\begin{array}{l}\text { IDENT- } \\
\text { strid }\end{array}$ & $\begin{array}{l}* \mathrm{~N}- \\
\text { ONS }\end{array}$ & $\begin{array}{l}* \mathrm{~F}- \\
\mathrm{ONS}\end{array}$ & $\begin{array}{l}* \mathrm{~S}- \\
\mathrm{ONS}\end{array}$ & FAITH \\
\hline /nkasjat/ & $* !$ & & & & & $*$ & & $*$ & \\
\hline /nasjat/ & & & & & & $*$ & & & * \\
\hline$\rightarrow /$ kassat/ & & & & & & & & $*$ & $*$ \\
\hline \multicolumn{10}{|l|}{ /rfu:f/ } \\
\hline /ru:f// & & & $*$ & & & & & & $*$ \\
\hline /rfu:f/ & $* !$ & & $*$ & & & & $*$ & & \\
\hline$\rightarrow /$ fu:f/ & & & & & & & $*$ & & $*$ \\
\hline
\end{tabular}

Hence, the child's grammar responsible for the production of Arabic cluster in the manner shown in the Tableaux can be suggested as:

\section{FAITH}

\section{CONCLUSION AND RECOMMENDATION}

This study investigated the truncation process of onset cluster in the early speech of a bilingual child whose two first languages are Arabic and English. The study provided us with two different grammatical hierarchies each one of which is responsible for the deletion of a particular segment and the pertaining of the other in each language. The child's simplification of the English cluster was consistent with findings of other results in that his production reflected conformity with the universally fixed onset constraint hierarchy. In his English production, the child repeatedly deleted 
the segment with the higher sonority. The grammatical hierarchy that was suggested to be responsible for the truncation of English onset cluster was:

\section{*COMPLEXonst $>$ >G-ONS $>>$ L-ONS $>>*$ FRICATIVE $\gg>$ N-ONS $>>$ F-ONS $>>$ S-ONS $>>$ FAITH}

In the child's Arabic production, however, the universally fixed onset constraint hierarchy was partially subverted especially in the production of the sequences formed by fricative followed by stop and stop followed by fricative. This sequence witnessed a truncation in favour of the fricative by the influence of IDENT-strid which is ranked higher relative to *F-ONS. The Arabic sequence formed by fricative followed by nasal was subject to epenthesis influenced by MAX-labial. The grammatical hierarchy responsible for the production of the Arabic consonantal sequences in the way discussed throughout the research was suggested as follows:

\section{*COMPLEXonset $>>$ *G-ONS $>>*$ L-ONS $>>$ MAX-labial, IDENT-strid $>>* N-O N S>>$ *F-ONS $>>$ *S-ONS $>>$ FAITH}

\section{RECOMMENDATION}

Further research on the truncation of Arabic onset clusters by monolingual children is required so that a pattern can be detected for the reduction of Arabic onset consonantal sequences into singletons.

\section{REFERENCES}

[1] Barlow, J. A. (1997). A Constraint-Based Account of Syllable Onsets: Evidence from Developing Systems. Unpublished doctoral dissertation, Indiana University.

[2] Carr, Philip. (1999). English Phonetics and Phonology. Blackwell Publishers: UK.

[3] Clements, G. N. (1990). The Role of the Sonority Cycle in Core Syllabification. In Kington, J. and Beckman, M. E. (eds.) Papers in Laboratory Phonology I: Between the Grammar and Physics of Speech, 283-333. Cambridge: Cambridge University Press.

[4] Daana, H.A. (2009). The Development of Consonant Clusters, Stress and Plural Nouns in Jordanian Arabic Child Language. PhD diss., the University of Essex: UK.

[5] Daana, H \& Khrais, S. (2018). The Acquisition of English and Arabic Onset Clusters: A Case Study. English Linguistics Research. 7 (1), 13-33. DOI: 10.5430/elr.v7n1p13.

[6] Gnanadesikan, A. (1995). Markedness and faithfulness constraints in child phonology (Rutgers Optimality Archive No. ROA67-0000). Amherst: University of Massachusetts.

[7] Kirk, C., \& Demuth, K. (2005). Asymmetries in the acquisition of word-initial and word-final consonant clusters. Journal of Child Language, 32(4), 709-734. "DOI: 10.1017/S0305000905007130".

[8] Levelt, Clara C., Schiller, Niels O. and Levelt, Willem J. (2000). The Acquisition of Syllable Types, Language Acquisition, 8 (3), 237- 264. "DOI: 10.1207/S15327817LA0803_2".

[9] Lleo, C., and Prinz, M. (1996). Consonant Clusters in Child Phonology and the Directionality of Syllable Structure Assignment. Journal of Child Language 23(1), 31-56." DOI: 10.1017/s0305000900010084".

[10] Ohala, D. K. (1996). Cluster Reduction and Constraints in Acquisition. Unpublished doctoral dissertation, University of Arizona. "http://hdl.handle.net/10150/290673". Accessed 30/5/2028.

[11] Pater, Joe (1997). Minimal Violation and Phonological Development. Language Acquisition 6 (3), $201-253$. "https://doi.org/10.1207/s15327817la0603_2".

[12] Pater, Joe, and Jessica A. Barlow (2003). Constraint Conflict in Cluster Reduction. Journal of Child Language 30, $487-526$. "https://doi.org/10.1017/S0305000903005658".

[13] Watson, Janet C. E. (2002). The Phonology and Morphology of Arabic. Oxford University Press: England.

Hana Asaad Daana received her PhD in Language Acquisition from Essex University in the United Kingdom in (2009). She is now an assistant professor in the Department of English Language and Literature in Princess Alia University College/Al-Balqa Applied University in Jordan. She teaches courses such as: Language Acquisition, English Syntax, English Phonetics and Phonology, Semantics, Sociolinguistics, and Psycholinguistics. Her research interests are in the field of First Language Acquisition and Arabic Dialectal Differences. She has published many articles in these two fields. 